\title{
Submission Unit Status
}

National Cancer Institute

\section{Source}

National Cancer Institute. Submission Unit Status. NCI Thesaurus. Code C70866.

An attribute that indicates the status of a submission unit being referenced in relation to a regulatory assessment. The status of a submission unit is assigned by the submitting organization. 